\title{
Tekla Mecsnóber
}

\section{'So leastward on'}

\section{Reduction and the Absurd in Samuel Beckett's Late Drama ${ }^{1}$}

The overall tendency towards reduction which ensued in Samuel Beckett's artistic career after his first non-stage (radio) play All That Fall in 1956, and which is a peculiarity instantly given away by the lessening number of pages and dramatic characters, is rather difficult to overlook. Another widespread view classifies Beckett's plays as belonging to the absurdist tradition, and the link between these two characteristics does not seem altogether unnatural considering the famous Beckettian statement of 1949 about a new art which would, rather absurdly (in a non-technical sense), prefer the expression that

there is nothing to express, nothing with which to express, nothing from which to express, no power to express, no desire to express, together with the obligation to express.

$$
\text { ('Three Dialogues') }{ }^{2}
$$

However, since no other absurdist playwright seems to have imposed as severe limitations on his work as Beckett did, the relationship between reductionism and the absurd appears to be, if not uneasy, at least not evident. One of the main concerns of this essay is to try to investigate how and why, in Beckett's case, these two trends should have become intertwined.

\footnotetext{
'The qouted phrase in the title comes from Worstward Ho 119. In what follows, references to Beckett's works will be given using the abbreviations listed in the Appendix. The page numbers refer to the editions listed in the bibliography.

2 "Three Dialogues," Disjecta 139. Like all of the dialogues, this notorious statement should, however, be taken with a (large) pinch of salt.
} 
I shall start with a brief description of Beckett's reductionism in his shorter plays (starting with All That Fall), with occasional references to his late prose. This will be followed by an attempt at interpreting these phenomena, and linking them to the absurdist tradition. Finally, I shall try to offer for consideration some very general attitudes which might have influenced Beckett in the creation of his peculiar reductionist variant of the absurd.

\section{DRAMA WRITING DEGREE ZERO}

E M Forster in his Aspects of the Novel made a seminal distinction between 'flat' and 'round' characters, the former being 'constructed around a single idea or quality, ${ }^{3}$ while the latter significantly more complex and capable of convincingly surprising the reader. ${ }^{4}$ It appears that Beckett's shorter plays can be described as exhibiting a move from the fairly 'round' towards the radically 'flat.' This statement would indeed apply not only in respect of characters, since such a reduction seems to be operating at all of what one might crudely describe as the three main sensuous 'faces' of dramatic representation: characters, stage action and the spoken word. ${ }^{5}$

Such is the radicalism, however, of Beckett's reductions, and the variety of modern literature after Forster conceived of his idea in 1927, that instead of this binary distinction it appears beneficial to adopt a more pluralistic one. Basing the metaphor, this time, on a slightly more complicated geometry, one could theoretically distinguish between phenomena of any number of dimensions, defined as their 'significant aspects' or 'relevant systems of meaning.' Of all these dimensions, then, Forster's 'flatness' would correspond to 'very few dimensions' (one or two), and his 'roundness' to 'sufficiently many to seem natural.' More significantly, though, the system would also invite an additional recognition of the two extreme cases of zero and infinitely many dimensions, which could, arguably be used to grasp the differences of such radical literary experiments as, for instance, Beckett's late drama or Joyce's late prose. ${ }^{6}$

\footnotetext{
${ }^{3}$ Forster 75.

${ }^{4}$ Forster 85 .

${ }^{5}$ I shall assume that representation, as an attempt to convey some sort of meaning or value through sensuous form, is a relevant aspect of most works of literature, if not art in general.

${ }^{6}$ This difference, summed up in the critical commonplace that 'Joyce puts in and Beckett takes out' (Feshbach 593), can be briefly described as follows. If, as I shall argue, Beckett's writing approaches infinitesimal dimensions, Joyce's (in Finnegans Wake) could be said to have a tendency towards infinity. The text of Finnegans Wake is striving to invite as many frames of reference as possible: words evoke several others in various languages, character configurations correspond to dozens of configurations of fictional or real persons, actions are identified with various other actions. There is no theoretical limit to the number of connections readers can make: the number of possible frames of
} 


\section{Characters}

Considering the dimensions related to characters first, one can argue that All That Fall in Mrs Rooney offers a sufficiently well-rounded character of several dimensions, with various aspects which determine and describe her, and along which she can be interpreted: nation, social status, religion, family, gender, age, physique, aspirations (death) and the basic condition (living on), with these last two dimensions being arguably the strongest. This bias points towards other plays, where we often find characters with fewer meaningful aspects to them. In a number of cases there seem to be two such aspects (e.g. gender and having to live on, as in Play), whereas perhaps more often there is only one overwhelming dimension, that of being human beings, of being confined and doomed to living on (as, for example, in $A W W 1, A W W 2$ or Quad). Indeed, this could be taken as the zero dimension of human being: a default void of any additional meaning.

A brief look at the names that Beckett gives his characters is relevant here. Mrs Rooney and Miss Fitt (of $A T F$ ) or Krapp (of $K L T$ ) bear names which, though emphasising one particular dimension ('ruiny,' 'misfit' and 'crap'), are socially and officially acceptable forms which sound 'normal' enough. So do the names of Ada and Henry $(E m b)$, which stress the aspect of familiarity (and family).

In contrast, Flo, $\mathrm{Vi}$ and $\mathrm{Ru}(C G)$ or Bam, Bem, Bim and Bom $(W W)$ seem to have been reduced to a status lower than that of socially recognizable human beings, with perhaps one real dimension: they are females (in $C G$ ) or males (in $W W$ ), with the indication that they are minimally distinct in that they are not each other and still retain some appearance of individuality. (In fact, the existence of Bem, Bim, and Bom is in itself questionable, as What Where could be interpreted, along with other pieces by Beckett, as mere mental occurrences within the closed space of a mind; in this case, Bam's.) ${ }^{7}$ A further step is the resort to solely gender distinctions, mostly abbreviated or pronominalised into generality: He, She $(R R I)$, W1, W2, M (Play), M, M1, W (btc), W (Rock). Similarly, some characters are reduced to the dimension of one function: Opener (Casc), Auditor (NI), Listener $(T T)$, Speaker $(P M)$. Beckett often does not even make a clear distinction between characters and other elements: set, movements, or music are repeatedly listed on a par with characters in his plays, as if reinforcing the sense of their severely reduced humanity.

reference is infinite. Although Beckett and Joyce are obviously extreme cases, the general tendencies towards limiting and multiplying frames of reference could have a wider application. (The avoidance of exact dimension numbers in the non-extreme cases is a consequence, and indication, of the nontriviality of exact assignations of concrete aspects.)

${ }^{7}$ See Jonathan Kalb on All That Fall as having reality only in Maddie's mind. 
What could be seen as zero dimensionality in this respect is the pure unmotivated algebraisation and numbering of characters, where the implication of the 'names' is mere difference: A, B, C (AWW2), A, B (RT1), A, B, C (RT2), or 1, 2, 3, 4 (Quad).

Another relevant aspect of dramatic characters is their visual appearance. This, of course, is lost (zero-dimensional) in the radio plays. That this might have been a powerful attraction for Beckett towards the genre of radio plays seems rather likely from the fact that he often uses disembodied voices in his stage and television plays as well: there is no visual aspect to the voices in Eh Joe, That Time, Footfalls, Ghost Trio, etc. Another bodiless quasi-character is point of view in Beckett's television plays, which actually appears as a separate character (E for 'eye') in his Film.

The visual fragmentation of characters is a further device typical of Beckett. Thus, the Listener is only a face in That Time; the bodies of W1, W2 and M are hidden in urns in Play; in Not I, one of the two characters is a mouth; in Nacht und Traume, two of the four characters are mere hands.

When characters do appear on stage in full, their individualising characteristics are minimised: nondescript grey and white hair, faces, and non-distinctive cloaks abound.

\section{Stage Action}

Similarly, stage action is also severely limited in Beckett's shorter plays. As this is another primarily visual aspect, the radio plays can be said to have this dimension, too, reduced to zero. ${ }^{8}$ The only later piece that contains action in open space seems to be Film, but even this closes the space up and, by the third and last part, confines it to a room, the characteristic venue of Beckett's plays. In the television plays, the movements within this room are very carefully plotted out by Beckett. As an extreme case of this, the numbered players of Quad move on fully determined repetitive tracks, rather like pieces on a game board, having no degree of freedom whatsoever. Indeed, in the later Beckett, a typical reduction of stage action is to 'movement' in the chess-like sense of 'pacing.'

The stage plays, apart from Krapp's Last Tape and Catastrophe, mostly limit the movement to one axis: the goad and the characters move horizontally along the edge of the stage in Act Without Words II and Come and Go, whereas the significant movement is vertical in Act Without Words I and Nacht und Traume. Often, stage movement has zero dimension, and the characters stand or sit inertly, as in Play or That Time.

\footnotetext{
${ }^{8}$ From a less visual point of view, All That Fall can, again, be seen as containing 'round', fairly manydimensional, lifelike action, which then becomes significantly more limited in the later pieces for the radio.
} 


\section{The Spoken Word}

Language was still 'round' in All That Fall, and through Irishisms and other peculiarities it reflected national, cultural, social and personal traits. In the later plays, Beckett seems to have put an emphasis on bleaching these frames of reference out of his plays, leaving behind only the denotative, primary meanings of words - or not even those. ${ }^{9}$ In a sense, the purest form of denotation could be achieved when no words are spoken on stage (as in AWW1, AWW2, Film). As the audience do not know the actual text of the piece, which in such cases is a set of bare stage directions, they are encountered, ideally, with only the pure extension, or referents (the things to which they refer), of these stage directions as they are acted out on stage. ${ }^{10}$ Other major examples of Beckett's efforts to reduce linguistic representation are the numerous speechless characters of his plays (C in FT2, Joe in $E J$, the Auditor in Not $I$ ), while the utterances of characters who do speak are also kept at a low number of common neutral words, frequently repeated.

Although the overall elimination of the spoken word from some plays appears to be more radical than mere repetitions, the latter also might be seen as the more severe of these reductions. For Beckett's repetitions do not only reflect a wearing away of possible particularities, or connotations, of meaning, but they frequently reveal a breach between the use of the word and any sort of meaning. Like Lucky's 'thinking aloud' in Waiting for Godot, Words'(s) repetitions of the same fragments of language in Words and Music to describe radically different concepts seems to suggest an underlying emptiness: what the torn veil of language reveals behind it might be Nothingness.

\section{Breath}

The most extreme example of Beckett's reductionism is, arguably, his roughly half-minute theatre piece Breath. Since character, stage action and language are all approaching the infinitesimal in the 'play', this is probably the least a dramatic piece can be and still not be nothing. Breath, of course, is not Beckett's last work, and I do not wish to argue for a chronologically smooth process of ever increasing

\footnotetext{
${ }^{9}$ I use 'denotation' here in a sense excluding any emotional, cultural or historical connotations, but including the logical duality of extension and intension.

${ }^{10}$ That Beckett had thought of trying to directly reach the referents, or the world behind the words, is illustrated by a famous statement of his from 1937: 'And more and more my language appears to me like a veil that must be torn apart in order to get at the things (or the Nothingness) behind it' (Beckett's German letter to Axel Kaun, transl Martin Esslin, Disjecta 171). This point will be taken up later again in this essay.

II See the quotation in the previous note. What I propose here does not exclude the possibility of some sort of meaning emerging from the connections of words with each other, without necessary reference to the external world.
} 
reductions in the writer's career. What seems, however, a sensible conclusion to this overview of the conventional constituents of character, stage action and the spoken word is that Beckett was apparently trying to reduce these representational aspects to as few dimensions as possible. Taking this to a logical extreme, he occasionally attempts a dangerous total reduction, that is he attempts to eliminate representation itself. He does this in drama, the most blatantly representational of all literary forms: reductio ad absurdum.

\section{DISCONNECTIONS}

Why would Beckett engage in such a seemingly irrational project of representing (for he was writing for the audience) without representations? In Beckett's case, one does not expect the reason to be mere lack of logic on the playwright's part. As the answer would seem to hinge on some separation of what represents and what should be represented, it might be useful to see whether any such idea would be borne out by the plays.

It has been mentioned that certain types of repetitions seem to question the necessary links between the use of a word and the conveyance of meaning. A similar breach between word and meaning is hinted at in Krapp's Last Tape, when the recorded Krapp utters words (memorable equinox and viduity, pp. 57, 59) which have become meaningless for the older Krapp. The latter episode is emphasised by Krapp's attempt to eliminate the breach by using a dictionary, which leaves him newly confused, as more words do not appear to guarantee more or clearer meaning:

[Reading from dictionary.] State - or condition - of being - or remaining - a widow - or - widower. [Looks up. Puzzled.] Being - or remaining? ...

(KLT 59)

A curious type of mismatch between referring word and the thing referred to is encountered in All That Fall, where the grossly exaggerated sound effects that follow the utterance of the corresponding word render the reality of the referent more than questionable. Of course, the fact that the sounds are highly at odds with Mrs Rooney's words only reinforce this discrepancy:

All is still. No living soul in sight. The word is feeding. The wind - [Brief wind.] - scarcely stirs the leaves and the birds - [Brief chirp.] - are tired singing. The cows - [Brief moo. $]$ - and sheep - [Brief baa. $]$ - ruminate in silence. The dogs - [Brief bark.] - are hushed and the hens - [Brief cackle.] 
- sprawl torpid in the dust. We are alone. There is no one to ask.

(ATF 32)

Words also become disconnected, in very late works by Beckett, on the textual level, as essential conjunctions, verbs, auxiliaries and inflections are lost:

And now. This night. Up at nightfall. Every nightfall. Faint light in room. Whence unknown. None from window. No. Next to none. No such thing as none.

(PM 265)

On somehow on. Anyhow on. Say all gone. So on. In the skull all gone. All? No. All cannot go. Till dim go.

(WWH 114)

Sometimes, dotted silences (also) indicate lost continuity within characters' trains of thought:

- sleep...no further...no more searching...to find him...in the dark...to see him...to say him...for whom...that's it...no matter...never him...never right...start again...in the dark...done with that...this time...it's the right one....we're there...nearly...finish -

(Casc 141)

Connections are regularly missing between voices and characters in the case of Beckett's disembodied voices and mute characters. Even more blatant is the breach with those characters who, like Krapp (KLT), manipulate their own externalised (recorded) voices, while remaining (largely) speechless themselves. This seems to be rather similar to Film, where the protagonist's sense of vision (E) is separated from his objectified self $(\mathrm{O})$.

Typical Beckettian characters include blind (Pozzo in Act II of $W G, \mathrm{Mr}$ Rooney in $A T F, \mathrm{~B}$ in $R T I$ ) and crippled (A in $R T I$ ) ones, whose connection to the world outside seems broken. There are breaches in human relationships, as lovers (Mr and Mrs Rooney in ATF; W1, W2, M in Play; the Speaker in PM) do not love their supposed loved ones. As a consequence, an air of being separated and alone surrounds most Beckettian characters.

As far as action is concerned, the only movement the Auditor in Not $I$ is capable of is four gradually lessening gestures of 'helpless compassion.' This, in a sense, is the counterpart of the artificial chess-like movement of pacing, an 
opposition which might indicate a split between natural areas of human activity. In addition, actions and outcomes, causes and effects are disconnected: there is no rational explanation for what happens in Act Without Words I, nor can the consciousness in Company arrive at solid conclusions on the basis of phenomena:

So he imagines to himself as voice and hearer pall. But further imagination shows him to have imagined ill. For with what right affirm of faint sound that it is a less faint made fainter by farness and not a true faint near head? Or of a faint fading to fainter that it recedes and not in situ decreases?'

(Comp 26)

Like Beckett's world, Beckett's God also seems to display disruptions of this kind. God's Word in the Bible is no longer certain, nor is its meaning:

It wasn't an ass colt at all, you know, I asked the Regius Professor. $\{\ldots\}$ Yes, it was a hinny he rode into Jerusalem or wherever it was on a hinny. [Pause.] That must mean something. [Pause.] It's like the sparrows, than many of which we are of more value, they weren't sparrows at all.'

God's actions do not seem to produce the intended effect:

first thought was...oh long after...sudden flash...she was being punished...for her sins $[\ldots]$...she suddenly realised...gradually realised...she was not suffering...imagine!..not suffering!..indeed could not remember...off-hand... when she had suffered less...unless of course she was...meant to be suffering...ha!..thought to be suffering... just as the odd time...in her life...when clearly intended to be having pleasure...she was in fact...having none...not the slightest

God's love for his creatures is then equally questionable and the notion itself is sufficient to provoke laughter:

"The Lord upholdeth all that fall and raiseth up all those that be bowed down." [Silence. They join in wild laughter. $\{\ldots\}]$

$\sqrt{2}$ Braces $(\{\})$ indicate my omissions. 
brought up as she had been to believe....with the other waifs...in a merciful...[Brief laugh.]...God... [Good laugh.]...

(NI 217, repeated once more on page

As God seems to be totally separated from the world, there can be no certainty about even his existence: the world is unable to operate as a sign referring to the divine signified.

While the dimension of various aspects of representation often approaches zero, Beckett's plays reveal a world where outcomes are disconnected from actions, effects from causes, signs from meanings, representations from the represented. Far from being without its logic, a project in which a playwright attempts to minimise representation and still somehow convey his meaning seems then to be a frighteningly consistent participation in a world of disconnections.

\section{BECKETT, THE ABSURD AND REDUCTIONISM}

As such disconnections deprive inference, meaning and rational thinking of their bases, it is not difficult to find in the Beckettian world the kin of the absurd in Camus's sense of a life lived solely for its own sake in a universe which no longer makes sense (because there is no God to resolve the contradictions). ${ }^{13}$ Whether or not there was a God for Beckett, there is certainly no successful communication with him in the writer's works. The created world is as unable to give evidence of God's existence or explain his meaning in creation as it is unable to provide explanations and meaningfulness in everyday matters. ${ }^{14}$

It seems reasonable to say, then, that Beckett's strongest link to the absurdist theatre is a shared sense of lost connections, lost origins, lost frames of reference. We have also seen that in order to convey this sense and emphasise disconnections, Beckett chose to radically reduce certain aspects of representation in his work. The

\footnotetext{
${ }^{13}$ Alvarez 15.

${ }^{14}$ Curiously, the etymology of the term absurd also goes back to rather Beckettian disconnections. According to the $O E D$, Latin surdus originally meant 'deaf and 'mute' as well as 'inaudible' and 'insufferable to the ear,' and with the addition of the intensifying (but normally disjunctive) prefix, it came to mean 'inharmonious,' 'unreasonable' and 'ridiculous.' Deaf and mute, blind and crippled characters, of course, mostly belong to farce, and the ridicule of such characters is now also part of the meaning of the word absurd and the tradition of the absurdist theatre.

Naturally, however, the laughter provoked by the absurdist theatre is not the easy laughter of comedy. To have pure comedy, as well as tragedy, there has to be a solid framework of meaning shared by playwright and audience (if not by all characters). As such a framework would be lacking in Beckett's view, it seems natural that after Waiting for Godot (a 'tragicomedy'), he ceased to use the terms 'tragedy' and 'comedy' in generic descriptions of his later plays.
} 
question asked in the introduction now arises again: What made Beckett decide by exactly this reductionist way to achieve his goal?

A possible aspect of the writer's eventual preferences can be sought in certain intellectual influences that could have had an effect on Beckett's attitudes towards representation. I propose to consider two systems of thought to which Beckett was exposed: Calvinist Protestantism and the philosophy of Descartes.

In Protestantism and Descartes, like in the theatre of the absurd, the question of representation is bound up with the relationships between word and meaning, body and mind, the world and God. Specifically, a typical concept of God in Protestantism is that of the transcendental God, who, in contrast with the immanent God of, for instance, sacramental Catholicism, does not dwell in the created world. ${ }^{13}$ As an effect of this, the world is tainted with imperfection and evil, and so is, as a consequence of the Fall of Man, the human body, which partakes of the corruption of the dedivinized world. Similarly, worldly signs are imperfect, even deceptive conveyors of pure meaning. The two basic types of faith (immanentist and transcendental) are, then, closely linked to two extreme attitudes towards signs, namely the iconophile and the iconophobe traditions, characterised by their respective trust and distrust of material representations. Protestantism's general affinity towards the latter can be seen attested to by its ascetic, puritanical trends as well as by its active iconoclasm in sixteenth and seventeenth-century England, and the controversies, in the same period, surrounding the use of figurative language. ${ }^{16}$

The philosophy of Descartes, one of Beckett's favourite thinkers, ${ }^{17}$ can, among other things, reinforce the clear Protestant preference for the non-material. In Descartes' Dualism, mind and body are strictly distinct, and indeed substantially different, the mind (res cogitans) coming from God and immortal, while the body, which belongs to the material world (res extensa), is perishable. ${ }^{18}$ Therefore, the body is inferior, and the Cartesian definition of existence (Cogito ergo sum, 'I think therefore I am') is solely based on the mind.

\footnotetext{
${ }^{15}$ I am referring to overall theological approaches, as distinct from everyday religious practice. See Endean 1981 on the transcendental and immanent God as alternative models for the relationship between God and the created world. Paul Tillich identifies a similar difference between sacramental and mystical faith, which he describes as the two basic ontological types of faith (1957, 58-64). See Tillich (1962) 96-97 on the 'dedivinization' of nature and iconoclasm in Calvinism.

${ }^{16} \mathrm{Cf}$. Chapter 2 of Gilman for Puritan attacks on figurative language in 16th- and 17th-century England. A parallel trend in science is described by Horne.

${ }_{17}$ Beckett's exceptional interest in and affinity to Descartes is indicated by the fact that, according to Deirdre Bair, he 'read Descartes voraciously and filled three large loose-leaf notebooks with his own thoughts and impressions as well as excerpts from critics and biographers' while he was at Trinity College (Bair 52). Also see Feshbach 593, 601.

${ }^{18}$ Fürst 40-41.
} 
I would like to argue that, although Beckett's endorsement of these systems of thought or even their premises (like the existence of God) might well be questioned, these mental patterns could still have had a lasting influence on his attitudes.

As early as 1937, Beckett described his literary ideal in religious terms as language's 'Descent to Hell,' as opposed to the 'apotheosis of the word,' or its 'Ascension to Heaven,' in Joyce's last work, Finnegans Wake. Significantly, he objects to the idea that there would be something 'paralysingly holy' in the word, and that this could prevent that 'terrible materiality of the word surface' from being 'capable of being dissolved.' Beckett names such a dissolution as the highest goal for writers of the age, as reaching it would mean that holes would be bored into 'vicious' language, 'until what lurks behind it - be it something or nothing- might seep through' and be reached. ${ }^{19}$

Although Beckett later dismissed this letter, one of his very few explicit written statements concerning his own works, as 'German bilge,' these ideas are far from being alien to the world of Beckett's later works. In these, too, the body is all too imperfect, stricken by numerous ailments and disabilities, inertia and impotence. Every act is a failure, and no attempt at correction can guarantee success:

All of old. Nothing else ever. Ever tried. Ever failed. No matter. Try again. Fail again. Fail better.

$$
(W W H, 101)^{20}
$$

One's efforts are incapable of bringing about success, and to minimise failure, the only reasonable choice is between ceasing to do, or be, altogether, or carrying on, with as little pain (and action) as possible.

Language likewise is imperfect, stricken by numerous ailments and disabilities, inertia and impotence. Every act of speech is a failure, and no attempt at correction can guarantee success: "Say for be said. Missaid. From now say for be missaid" $(W W H, 101)$.

One's efforts are incapable of bringing about perfect communication, and to minimise miscommunication, the only reasonable choice is between ceasing to say altogether and carrying on, with as few words and misunderstandings as possible. Beckett, an artist having an obligation to express, though nothing with which to express, chose the second option:

So leastward on. ${ }^{21}$

${ }^{19}$ German letter to Axel Kaun, transl Martin Esslin, Disjecta 172, passim.

${ }^{20} \mathrm{Cf}$. 'Any others would do as ill. Almost any. Almost as ill.' (WWH 105) 


\section{APPENDIX}

The dates refer to the year of writing. E (for English) and F (for French) indicate the language in which the work was originally written. Th, R, and TV indicate whether the piece was intended for the theatre, radio, or television.

ATF, All That Fall, 1956, E, R

AWW1, Act Without Words I, 1956, (F), Th

AWW2, Act Without Words II, 1956, (F), Th

Bre, Breath, 1969, E, Th

btc, ...but the clouds..., 1976, E

Cat, Catastrophe, 1982, F, Th

Casc, Cascando, 1962, F, F.

CG, Come and Go, 1965, E, Th

Comp, Company, 1977, E, Prose

EJ, Eh Joe, 1965, E, TV

Emb, Embers, 1959, E, R

FF, Footfalls, 1975, E, Th

Film, 1963, (E), Film:

GT, Ghost Trio, 1975, E, TV

KLT, Krapp's Last Tape, 1958, E, Th

NI, Not $I, 1972$, E, Th

NT, Nacht und Traume, 1982, (?), TV

\footnotetext{
${ }^{21}$ It is possible to argue that the same can be applied to the late Joyce as well, as the diffuse abundance of Finnegans Wake, just like Beckett's reductionism, seems to derive from the idea of the imperfection of language. The main difference is that Joyce does not mistrust language and representation as such, and does not deny the possibility of making sufficient meaning by making a constant effort. For him, increasing the number of words and semantic systems involved increases the possibility of understanding rather than misunderstanding. As with Beckett, these views can be set against a background of theology, and in particular immanentist and iconophile trends of Catholicism. For Joyce, there is always a chance for success after failure: the Fall is always followed by resurrection in Finnegans Wake. In Beckett, even failure fails: the rope breaks or is pulled away, and 'God upholdeth,' depriving one of a perfect $\mathrm{F} /$ fall and the expectation of resurrection.
} 
OI, Ohio Impromptu, 1980, E, Th

Play, 1962-3, E, Th

PM, A Piece of Monologue, 1979, E, Th

Quad, 1982, (?), TV

Rock, Rockaby, 1979-80, E, Th

RR1, Rough for the Radio I, 1961, F, R

RR2, Rough for the Radio II, early 1960s, F, R

RT1, Rough for the Theatre $I, 1950 \mathrm{~s}, \mathrm{~F}, \mathrm{Th}$

RT2, Rough for the Theatre II, 1950s, F, Th

TT, That Time, 1974-5, E, Th

WM, Words and Music, 1961, E, R

WW, What Where, 1983, E, Th

WWH, Worstward Ho, 1981, E, Prose

\section{BIBLIOGRAPHY}

Samuel Beckett: Collected Shorter Plays. London and Boston: Faber and Faber, 1984.

Samuel Beckett: Disjecta: Miscellaneous Writings and a Dramatic Fragment (ed. Ruby Cohn). London: Calder, 1983.

Samuel Beckett: Nohow On (Company, Ill Seen Ill Said, Worstward Ho). Paris, London and New York: Calder, 1992.

Samuel Beckett: Waiting for Godot. London and Boston: Faber and Faber, 1965 (2nd ed).

Alvarez, A: Beckett. London: Fontana, 1992 (2nd ed).

Bair, Deirdre: Samuel Beckett: A Biography. London: J. Cape, 1978.

Endean, Philip, SJ: "The Spirituality of Gerard Manley Hopkins," The Hopkins Quarterly, 8 (1981) 107-129.

Feshbach, Sidney: "On Names in James Aloysius Augustine Joyce and Samuel Barclay Beckett," The Massachussets Review, 34 (1993) 593-615. 
Fletcher, Beryl S et al: A Student's Guide to the Plays of Samuel Beckett. London and Boston: Faber and Faber, 1978.

Forster, E M: Aspects of the Novel. London: Penguin, 1962 (First published in 1927).

Fürst, Mária: Bevezetés a filozófiába. Budapest: Icon, 1993.

Gilman, Ernest B: Iconoclasm and Poetry in the Reformation: Down Went Dagon. Chicago and London: University of Chicago Press, 1986.

Horne, C J: "Literature and Science" in the New Pelican Guide to English Literature Vol. 4., ed. Boris Ford, London: Penguin, 1991, pp.135-150.

Kalb, Jonathan: "The mediated Quixote: the radio and television plays, and Film" in Pilling 124-144.

Pilling, John, ed: The Cambridge Companion to Beckett. Cambridge: CUP, 1994.

Renton, Andrew: "Disabled figures; from the Residua to Stirrings Still" in Pilling 167-183.

Tillich, Paul: Dynamics of Faith. New York etc.: Harper and Row, 1957.

Tillich, Paul: A History of Christian Thought. London: SCM Press Ltd, 1968. 